\title{
Current-Use Pesticides in New Zealand Streams: Comparing Results from Grab Samples and Three Types of Passive Samplers
}

Kimberly J. Hageman, ${ }^{1 *}$ Christopher H.F. Aebig, ${ }^{2}$, Kim Hoang Luong, ${ }^{3}$ Sarit L. Kaserzon, ${ }^{4}$ Charles S. Wong, ${ }^{3}$ Tim Reeks, ${ }^{4}$ Michelle Greenwood, ${ }^{5}$ Samuel Macaulay, ${ }^{6}$ Christoph D. Matthaei $^{6}$

${ }^{1}$ Department of Chemistry \& Biochemistry, Utah State University, Logan, USA

${ }^{2}$ Department of Chemistry, University of Otago, Dunedin, New Zealand

${ }^{3}$ University of Winnipeg, Winnipeg, Canada

${ }^{4}$ Queensland Alliance for Environmental Health Sciences (QAEHS), The University of Queensland, Brisbane, Australia

${ }^{5}$ National Institute of Water and Atmospheric Research, Christchurch, New Zealand

${ }^{6}$ Department of Zoology, University of Otago, Dunedin, New Zealand

*Corresponding Author

E-mail: kim.hageman@usu.edu; Phone: 1-435-797-0114 


\section{ABSTRACT}

New Zealand uses more than a ton of pesticides each year; many of these are mobile, relatively persistent, and can make their way into waterways. While considerable effort goes into monitoring nutrients in agricultural streams and programs exist to monitor pesticides in groundwater, very little is known about pesticide detection frequencies, concentrations, or their potential impacts in New Zealand streams. We used the 'Polar Organic Chemical Integrative Sampler' (POCIS) approach and grab water sampling to survey pesticide concentrations in 36 agricultural streams in Waikato, Canterbury, Otago and Southland during a period of stable stream flows in Austral summer 2017/18. We employed a new approach for calculating site-specific POCIS sampling rates. We also tested two novel passive samplers designed to reduce the effects of hydrodynamic conditions on sampling rates: the 'Organic-Diffusive Gradients in Thin Films' (o-DGT) aquatic passive sampler and microporous polyethylene tubes (MPTs) filled with Strata-X sorbent. Multiple pesticides were found at most sites; two or more were detected at $78 \%$ of sites, three or more at $69 \%$ of sites, and four or more at $39 \%$ of sites. Chlorpyrifos concentrations were the highest, with a maximum concentration of $180 \mathrm{ng} / \mathrm{L}$. Concentrations of the other pesticides were generally below $20 \mathrm{ng} / \mathrm{L}$. Mean concentrations of individual pesticides were not correlated with in-stream nutrient concentrations. The majority of pesticides were detected most frequently in POCIS, presumably due to its higher sampling rate and the relatively low concentrations of these pesticides. In contrast, chlorpyrifos was most frequently detected in grab samples. Chlorpyrifos concentrations at two sites were above the 21-day chronic 'No Observable Effect Concentration' (NOEC) values for fish and another two sites had concentrations greater than $50 \%$ of the NOEC. Otherwise, concentrations were well-below NOEC values, but close to the New Zealand Environmental Exposure Limits in several cases. 
CAPSULE: A number of current-use pesticides were found in New Zealand streams; detection frequencies and concentrations obtained with three passive samplers and grab water samples were compared.

\section{INTRODUCTION}

Many of the pesticides commonly used in agriculture today are sufficiently water soluble and persistent to enter nearby waterways, usually via surface runoff (Szöcs et al. 2017). Here, they have the potential to impact aquatic organisms, especially when present as complex mixtures of toxicants (Bradley et al. 2017, Nowell et al. 2018) and/or in the presence of other agricultural stressors such as elevated nutrients, fine sediment, water temperature or decreased stream flow (Liess et al. 2016). For these reasons, pesticide concentrations are regularly monitored in agricultural waterways in many parts of the world, including in the European Union (Integrated River Basin Management for Europe) and the United States (USGS Pesticide National Synthesis Project). In New Zealand, where more than a ton of pesticide active ingredients (including insecticides, herbicides, and fungicides) are used each year (Manktelow et al. 2005, Chapman 2010), pesticides are regularly monitored in groundwater (Close and Skinner 2012) and nutrients are regularly monitored in freshwaters (Ministry for the Environment \& Stats NZ 2017). However, pesticide monitoring in surface waters does not occur, and no comprehensive survey of pesticides in surface waters has been conducted. Thus, very little is known about pesticide detection frequencies, concentrations, or their potential ecological impacts in New Zealand streams. This information is urgently needed because a number of pesticides have been identified for reassessment review by the NZ Environmental Protection Authority (New Zealand Environmental Protection Authority 2018). Moreover, New Zealand still uses several pesticides that have been 
banned elsewhere (e.g. atrazine, chlorpyrifos, and the neonicotinoids) due to concerns about effects on non-target organisms, including freshwater organisms.

Several approaches exist for sampling pesticides and other contaminants in aquatic systems (Bundschuh et al. 2014). Spot grab water sampling is the most common and straight-forward approach; however, pesticides may not be detected due to low sample volumes (usually 0.5 to 1 L) and since measured concentrations are obtained for a snapshot in time, results may be misleading in dynamic systems (Bundschuh et al. 2014). Active sampling devices can be used to sample larger volumes, but equipment is expensive, complex and requires a power source. An alternative is passive sampling, which pre-concentrates dissolved-phase analytes in situ from a relatively large volume of water and, if in the uptake mode, produces a time-weighted average (TWA) concentration (Zabiegała et al. 2010). Passive sampling theory, and the approaches used to calculate concentrations in water from those in samplers, have been described in many previous publications (Vrana et al. 2005, Alvarez et al. 2007, Gong et al. 2018). In brief, passive water samplers contain a sorbent to which freely dissolved pesticides bind as water flows past the sampler and most samplers use a diffusive membrane to control uptake rates. Passive samplers are usually deployed at field sites for 10-30 days; analytes are then extracted from the sorbent for quantification.

The 'Polar Organic Chemical Integrative Sampler' (POCIS) (Alvarez et al. 2004) is one of the most commonly used and best characterized passive samplers for polar and mid-polarity analytes. Despite its popularity, a drawback with POCIS is that analyte sampling rates are affected by environmental factors such as hydrodynamic conditions and water temperatures, and attempts to 
use performance reference compounds to address this issue have had limited success (Harman et al. 2012, Fauvelle et al. 2017). This issue arises because the thickness of the water boundary layer (WBL) through which analytes cross to enter the sampler is affected by the water flow rate; likewise, water temperature controls the analyte diffusion rate through the WBL. Since POCIS sampling rates are generally measured at only a few flow rates and temperatures, sampling rates that represent actual field conditions are usually not available. To address these issues, Djomte $e t$ al. 2018 recently introduced a new model for calculating site-specific POCIS sampling rates that takes into account flow and temperature effects. Researchers have also begun introducing alternative samplers that are designed such that the WBL has a reduced impact on sampling rates. These samplers use a relatively thick diffusive membrane so that the sampling rate is controlled by the rate at which analytes cross the diffusive membrane instead of the WBL.

The first objective of this study was to identify which pesticides are present in New Zealand agricultural streams and to determine their frequencies of detection, concentrations, and potential to impact aquatic organisms. Considering that freshwater nutrient concentrations are welldocumented in New Zealand and because fertilizers and pesticides are often used on the same fields, our second objective was to determine if nutrient data could be used to identify stream sites with relatively high pesticide concentrations. To address these objectives, we measured pesticides and nutrients in 36 streams in four Regions across New Zealand. To obtain time-integrated pesticides concentrations, we used POCIS with 0.132-mm thick polyethersulfone (PES) diffusive membrane, at all sites. We also collected grab water samples at all sites to generate complementary data. Since our study included 36 stream sites with a range of water flow rates and temperatures, 
we explored the new approach introduced by Djomte et al. (2018) for calculating site-specific POCIS sampling rates.

Our third objective was to test two novel passive samplers and to evaluate their applicability for measuring pesticide concentrations in streams. The first of these samplers was a new configuration of the 'Organic-Diffusive Gradients in Thin Films' (o-DGT) aquatic passive sampler (Stroski et al. 2018) that uses a $0.90-\mathrm{mm}$ polyacrylamide diffusive gel and Septa ${ }^{\mathrm{TM}} \mathrm{ZT}$ sorbent. The second novel sampler we tested was composed of 2-mm thick microporous polyethylene tubes (MPTs) filled with Strata-X sorbent, which is chemically equivalent to $\operatorname{Septa}^{\mathrm{TM}} \mathrm{ZT}$. This design was similar to that previously described for glyphosate uptake using $\mathrm{TiO}_{2}$ gels as the sorbent (Fauvelle et al. 2017) and for per- and polyfluoroalkyl substance (PFAS) uptake using Strata X-AW as the sorbent (Kaserzon et al. 2019).

\section{METHODS \& MATERIALS}

\subsection{Sampling Sites, Approach, and Dates}

Pesticide concentrations were measured in 36 agricultural streams located in four Regions of New Zealand. Twelve of the stream sites were located in the Waikato Region on the North Island of New Zealand while another 24 were located on the South Island of New Zealand (six in Otago, six in Southland, and 12 in Canterbury) (Figure 1 and Supplemental Information (SI) Table S1); exact locations were not included to protect land owner privacy. We selected sites with relatively high nutrient concentrations, as shown in previous studies, based on the assumption that pesticide and nutrient concentrations would be correlated (see second objective). Each site was classified 
according to the dominant land use observed at the time of sampler deployment and retrieval in a 100-200 m radius surrounding the site. The resulting four riparian land use categories were dairy/beef/sheep pasture (27 sites), cropland (three sites), native shrubs or forest (three sites), and lifestyle blocks (i.e. small farms operated for pleasure or supplemental income) (three sites). The majority of sites were surrounded by pasture because this is a dominant land use in New Zealand and because when last reported in 2005, the majority of the insecticides and herbicides used in New Zealand were applied to dairy/beef/sheep pasture (Manktelow et al. 2005, Chapman 2010). Pasture type was not further differentiated because reliable classification could not be achieved without surveying land owners and because pastures in New Zealand are often used for more than one type of animal.

Photos of each passive sampler type are shown in Figure S1. Detailed descriptions of passive sampler preparation, deployment, and extraction methods, as well as grab sampling methods, are provided in Section 1 of the SI. POCIS were deployed at all 36 sites; the o-DGT and MPT samplers were co-deployed with POCIS at the 12 Canterbury sites. The Canterbury Region was selected for comparing all sampling approaches because of high agricultural intensity. POCIS samplers were found damaged upon retrieval at Waikato Site 4 and all passive samplers were missing upon retrieval at Canterbury Site 7. Grab samples for pesticide and nutrient analysis were collected at the time of passive sampler retrieval. Samples were collected during December 2017 and January 2018 (i.e. during Austral summer). Due to logistical limitations, sampling dates varied between Regions and passive sampler deployment times ranged from 22 to 24 days (Table S2). The sampling period was characterized by unusually dry and hot weather, with negligible precipitation, 
that affected most of New Zealand between November 2017 and February 2018 (National Institute of Water and Atmosphere 2018).

Each type of passive sampler was deployed in triplicate. Grab samples were collected in triplicate at three sites; single samples were collected otherwise. Nutrient samples were always collected in triplicate. At each site, passive samplers, two temperature/light loggers (Hobo pendant $8 \mathrm{~K}$ data loggers, Onset Computer Corporation, Massachusetts, USA), and two passive flow monitors (PFMs) were attached to a $1.5-\mathrm{m}$ steel stake driven into the streambed. Water temperature was logged every $30 \mathrm{~min}$ and averaged for the entire period (Table S1). PFMs were prepared from gypsum dental plaster as described previously (Kaserzon et al. 2014) and used to estimate the water flow velocity over the surface of samplers (Table S1). Temperature/light loggers and PFMs were missing upon retrieval at Waikato Site 4.

\subsection{Analyte quantification}

Analytes in POCIS, o-DGT, and grab sample extracts were quantified at the University of Winnipeg with an Agilent (Mississauga, ON) 6410B tandem mass spectrometer (MS/MS) with electrospray ionization in both positive and negative mode using multiple reaction monitoring (MRM). Analytes were separated with an Agilent 1200 Series ultra-high-performance liquid chromatography (UHPLC) system and a Phenomenex (Torrance, CA) Kinetex XB- $\mathrm{C}_{18}$ column (50 $\mathrm{mm} \times 2.1 \mathrm{~mm} \times 1.7 \mu \mathrm{m}$ particle size) with a $\mathrm{C}_{18}$ SecurityGuard ULTRA Cartridge. Target analytes, with respective isotopically labelled internal standards, and method detection limits are listed in Table S3; their physicochemical properties are listed in Table S4. All other details about the instrumental method have been described previously (Challis et al. 2016). 
Analytes in MPT extracts were quantified at The University of Queensland using an AB/SCIEX (Ontario, Canada) 6500 QTRAP system with electrospray ionization using positive and negative ionization based on a scheduled multiple reaction monitoring (MRM) switching process. Analytes were separated with a Shimadzu Nexera HPLC system (Kyoto, Japan) and Phenomenex biphenyl column $(50 \mathrm{~mm} \times 2.1 \mathrm{~mm} \times 2.6 \mu \mathrm{m}$ particle size $)$ with a Kinetex EVO $\mathrm{C}_{18}$ pre-injector column. Target analytes, with respective isotopically labelled internal standards, and method detection limits are listed in Table S5. All other details about the instrumental method have been described previously (Kaserzon et al. 2017).

\subsection{Quality Assurance}

Two laboratory blanks were prepared per sample type (POCIS, o-DGT, and grab); these underwent all sample processing steps and were processed alongside real samples. Laboratory blank concentrations were divided by the average number of sample deployment days, which was 24 days (Table S2), and the sampling rate (Table S7) to obtain an equivalent concentration in water. These concentrations were then multiplied by three to obtain sampler-specific method detection limits (MDLs) (Table S3). Four POCIS field blanks, three o-DGT field blanks, and four grab sample field blanks were collected by bringing each sampler type to the field during passivesampler retrieval and then extracting and processing them in the same way as real samples. Most field blank concentrations were lower than method detection limits, although those for imidacloprid in POCIS and grab samples were slightly higher (Table S6). Three solvent blanks

and three laboratory procedural blanks, which underwent all processing steps, were processed 
alongside real samples. In addition, three MPT field blanks were used at the time of passive sampler retrieval. No target analytes were detected in laboratory or field blanks.

The use of two different laboratories and instruments with different detection limits has the potential to introduce systematic error in data analysis. Nonetheless, we have confidence in our comparison of data because (a) the concentrations of pesticides that were detected at both laboratories were similar, (b) the detection frequency was generally highest for POCIS, indicating that the lower sensitivity of the University of Winnipeg laboratory's UHPLC was not a limiting factor, and (c) isotopically labelled internal standards were used at both laboratories.

\subsection{Calculation of Pesticide Concentrations in Water from Passive Water Samplers}

Pesticide concentrations in water $\left(C_{\mathrm{w}}\right)$ were calculated using Equation 1, which is found in Alvarez 2010 and other references that describe passive sampling theory.

$$
C_{\mathrm{W}}=\frac{N_{\mathrm{s}}}{R_{\mathrm{s}} t} \quad(\text { Equation 1) }
$$

where $R_{\mathrm{s}}$ is the sampling rate $\left(\mathrm{L}\right.$ day $\left.{ }^{-1}\right), t$ is the deployment time (days), and $N_{\mathrm{s}}$ is the mass of chemical accumulated in the sampler at time $(t)$. The theoretical development of this equation is briefly described in SI Section 2. Sampling rates obtained from the literature for POCIS and oDGT samplers, and from previously unpublished laboratory calibration studies for MPT samplers, are provided in Table S7. The POCIS sampling rates listed in Table S7 are typical of those used in most studies; however, stream hydrodynamic conditions and water temperatures are known to affect POCIS sampling rates (Djomte et al. 2018). Djomte et al. recently used laboratory 
experiments to develop equations for estimating temperature-dependent POCIS sampling rates under flowing $(6-21 \mathrm{~cm} / \mathrm{s})$ and stagnant $(<6 \mathrm{~cm} / \mathrm{s})$ conditions for 12 pesticides, including atrazine. We used the Djomte equations (SI Section 3) and atrazine Arrhenius parameters (Table S8) to calculate atrazine POCIS sampling rates specific for the temperatures and flow conditions at our study sites (Table S9). We then compared the calculated atrazine concentrations obtained using the generic POCIS sampling rate to those obtained using site-specific sampling rates.

\subsection{Nutrient Sampling and Quantification}

At each site, triplicate samples for nutrient analysis were collected in 50-mL falcon tubes (APHA 1998) at the same time and from the same locations as grab samples. Samples were kept cool using ice packs in the field and during transport. Samples were filtered through a 0.7-mm glass fiber filter and then stored frozen for $<30$ days before analysis. Quantification of dissolved inorganic nitrogen (DIN) and dissolved reactive phosphorus (DRP) was conducted at the University of Otago using standard, colorimetric protocols (APHA 1998) with a SANPlus segmented flow autoanalyzer (Skalar Analytical B.V., Breda, The Netherlands).

\subsection{Statistical Analysis}

Pearson correlation analysis, using Excel 2016, was used to determine if individual pesticide concentrations, or the sum of detected pesticide concentrations, were related to the corresponding nutrient concentrations (DIN, DRP) at each site. 


\section{RESULTS and DISCUSSION}

\subsection{Detection Frequencies}

The seven pesticides targeted for analysis in POCIS, o-DGT, and grab samplers were all detected in this study. These were atrazine, chlorpyrifos, clothianidin, diazinon, 2,4-dichlorophenoxyacetic acid (2,4-D), imidacloprid, and thiamethoxam. Of these pesticides, three (atrazine, 2,4-D, and imidacloprid) were also on the target analyte list used for the MPT samplers deployed at the Canterbury sites, and all were detected. When results for all sampling approaches were considered, the percentage of agricultural stream sites (out of 36 in total) where each pesticide was detected was $83 \%$ for chlorpyrifos, $72 \%$ for atrazine, $67 \%$ for diazinon, $53 \%$ for $2,4-\mathrm{D}, 22 \%$ for imidacloprid, $8 \%$ for clothianidin, and 3\% for thiamethoxam. Atrazine and chlorpyrifos were also among the most commonly detected pesticides in a survey of anthropogenic organics in US streams (Bradley et al. 2017) and in a literature review summarizing the global occurrence of priority substances and chemicals of emerging concern in surface and ground waters (Sousa et al. 2018).

A number of pesticides and pesticide degradation products were quantified in MPT samplers (Table S5) that were not quantified in the other sample types (Table S3). From this list, seven pesticides and two pesticide degradation products were detected. The percentage of sites (out of the 12 Canterbury sites, minus one lost MPT sampler) where each of these chemicals were detected was $100 \%$ for both terbuthylazine and desisopropyl atrazine, $82 \%$ for 2-methyl-4chlorophenoxyacetic acid (MCPA), 55\% for triclopyr, 45\% for both desethyl atrazine and metsulfuron methyl, $27 \%$ for both haloxyfop and propiconazole, $18 \%$ for simazine, and $9 \%$ for 
diuron. Desethyl atrazine and desisopropyl atrazine are degradation products of atrazine (Singh et al. 2018). All pesticides on this list are herbicides, with the exception of propiconazole, which is a fungicide; diuron can also be used as an algicide.

The two organophosphate insecticides (chlorpyrifos and diazinon) frequently detected in our study are on the NZ Environmental Protection Authority's Priority Chemical List (New Zealand Environmental Protection Authority 2018), which lists chemicals most in need in review for reassessment in New Zealand. Chlorpyrifos is particularly controversial (New York Times 2018) due to evidence that it causes cognitive deficits and intellectual disability in children, but also because of toxicological effects on freshwater insects, fish, and pollinators (John and Shaike 2015). Atrazine is a triazine herbicide that presents a number of potential human and ecological health problems (Singh et al. 2018) and was banned in the European Union in 2003 due to exceedances in drinking water and groundwater threshold concentrations (Bethsass and Colangelo 2013). Clothianidin, imidacloprid, and thiamethoxam are neonicotinoid insecticides; these three chemicals were completely banned from outdoor use in Europe in 2018 (European Union Policies Information \& Services 2018). Neonicotinoid insecticides are well-known for their toxicity to pollinators (Goulson 2018), but there is also evidence that they are toxic to many freshwater organisms and may pose serious threats to freshwater ecosystems (Sánchez-Bayo et al. 2016). While acute and chronic toxicities of neonicotinoids vary among aquatic arthropods by six orders of magnitude, the more sensitive species exhibit short-term lethal effects below $1 \mu \mathrm{g} / \mathrm{L}$ (Morrissey et al. 2015). Finally, 2,4-D is a systematic herbicide used to control broadleaf weeds; Islam et al. 2018 recently reviewed its fate in the environment and found evidence for concern about its effects on sensitive organisms. 
Previous studies have shown that chlorpyrifos is ubiquitous in the New Zealand environment. It was the most frequently detected pesticide in a survey of chlorinated pesticides in New Zealand stream sediments, having been detected at $87 \%$ of the 15 stream sites in that study (Shahpoury et al. 2013). It has also been found in New Zealand honey bees (Urlacher et al. 2016) and undergoes atmospheric transport to remote locations in the Southern Alps in New Zealand (Lavin et al. 2012, Lavin and Hageman 2013, Wu et al. 2017). To the best of our knowledge, diazinon has not been previously targeted for analysis in New Zealand freshwaters, or in other environmental matrices. The transport of terbuthylazine into New Zealand waterways from its application on planted forests has been investigated previously (Rolando et al. 2017). Terbuthylazine was the most commonly detected pesticide in the most recent groundwater survey in New Zealand (Close and Skinner 2012). Other pesticides that were detected in both our study and in the most recent groundwater survey were chlorpyrifos, desethyl atrazine, and simazine; however, the target analyte lists were not identical and the groundwater survey did not target neonicotinoids. To the best of our knowledge, our study is the first to include neonicotinoids as target analytes for measurement in freshwaters in New Zealand. However, imidacloprid and thiamethoxam (as well as two other neonicotinoids, acetamiprid and thiacloprid) have been detected in honey from New Zealand hives (Mitchell et al. 2017).

The number of pesticides detected out of the seven targeted for analysis at all sites is represented by the bars in Figure 2. Several of these pesticides were found at most sites; two or more were detected at $78 \%$ of sites, three or more at $69 \%$ of sites, and four or more at $39 \%$ of sites. Two sites with riparian native shrubs/forest in the Waikato Region were the only ones where no pesticides 
were detected. It is notable that three or four pesticides were consistently detected at all six Southland sites, which were all surrounded by dairy/beef/sheep pasture (Figure 2); diazinon was detected at all six sites while both chlorpyrifos and 2,4-D were detected at five sites.

The numbers above the bars in Figure 2 show the number of additional pesticides from the MPT target analyte list that were also detected at the Canterbury sites. These show that up to six further pesticides, above the main set of seven pesticides targeted in our full study, can also be present in New Zealand streams. Other pesticides not on our target analyte lists may also be present.

\subsection{Pesticide Concentrations}

The mean concentrations of each pesticide at each site and in each sample type are provided in Tables S11 and S12-S17). Concentrations of the seven pesticides targeted for analysis at all sites (except for thiamethoxam, which was only detected at one site) are also shown in Figure 3. In these tables and this figure, atrazine concentrations in POCIS were calculated with the generic sampling rate (Table S7); concentrations calculated with site-specific sampling rates will be discussed later. The highest concentrations were generally observed for chlorpyrifos, with a maximum concentration of $180 \mathrm{ng} / \mathrm{L}$ measured in the grab samples at Waikato Site 1, which was surrounded by dairy/beef/sheep pasture, and Canterbury Site 7, which was surrounded by a lifestyle block. Concentrations of the other pesticides were generally below $20 \mathrm{ng} / \mathrm{L}$, with the exception of high concentrations of 2,4-D (210 ng/L measured in the grab sample, $74 \mathrm{ng} / \mathrm{L}$ measured with POCIS) at Waikato Site 6. No significant differences $(p<0.05$ in all cases) were observed when comparing pesticide concentrations between Regions (one-way ANOVAs, data not shown). 
In the MPT samplers from the Canterbury sites, the concentrations of the two atrazine degradation products (atrazine desethyl and desisopropyl atrazine), metsulfuron methyl, propiconazole, simazine, and haloxyfop were all less than $10 \mathrm{ng} / \mathrm{L}$. Higher concentrations of MCPA, and triclopyr were measured. In addition, the terbuthylazine concentrations in MPT samplers were higher than for any other pesticides, but its concentrations in water could not be determined because sampling rates have not been measured for this compound. Future work should include measurement of sampling rates for additional analytes with MPT samplers using the methods described in Fauvelle et al. 2017 and Kaserzon et al. 2019).

An extensive list of targeted anthropogenic organics ( 719 chemicals) were surveyed in 38 streams in the USA Bradley et al. 2017. Since that study also reported data for the seven pesticides we targeted at all of our stream sites, we compared our results to theirs for pesticide detection frequencies, maximum concentrations, and median concentrations (Table S18). Overall, detection frequencies were similar in the two studies although diazinon was detected more frequently in our survey and the reverse was true for thiamethoxam. The maximum and median concentrations for most pesticides were considerably lower in our study than in that by Bradley et al.. Chlorpyrifos concentrations in our survey were considerably higher than those reported by Bradley et al., but were comparable to the worldwide median chlorpyrifos concentration in surface and groundwater (Sousa et al. 2018) (Table S18). Chlorpyrifos concentrations above $100 \mathrm{ng} / \mathrm{L}$ were also reported in the Tagus River Valley in central Spain (Rico et al. 2019).

The review by Sousa et al. (2018) indicated that four studies reported organic pollutant concentrations in Australian streams since 2012 and three included target analytes on our lists. The 
maximum clothianidin, imidacloprid, and thiamethoxam concentrations in rivers around Sydney were 420, 4560, and $200 \mathrm{ng} / \mathrm{L}$, respectively (Sánchez-Bayo and Hyne 2014). The atrazine, atrazine desethyl, desisopropyl atrazine, and simazine concentrations in streams from a horticultural catchment in southeastern Australia were 10-20, 1, $1300 \mathrm{ng} / \mathrm{L}$, and 50-670 ng/L, respectively (Allinson et al. 2014). With the exception of desisopropyl atrazine, all of these concentrations are considerably higher than those we measured (Figure 3, Table S9). In addition, a number of other herbicides (dichlorvos, hexazinone, metalazyl, metribuzin, pendimethalin, prometryn, and terbutryn) that were on our MPT target list for Canterbury sites were detected in Australian studies, but not detected in our study (Allinson et al. 2014, Allinson et al. 2016).

The relatively high frequencies of detection and high concentrations of chlorpyrifos found in our study are concerning and warrant further investigation, especially since chlorpyrifos is on the NZ Environmental Protection Authority's Priority Chemical List (New Zealand Environmental Protection Authority 2018). We hypothesize that the concentrations of the pesticides we measured were considerably lower than they would be in a normal New Zealand summer with more precipitation and therefore more run-off events. Surface run-off typically increases pesticide concentrations in streams by several orders of magnitude, especially near the start of the precipitation event (Morrissey et al. 2015, Novic et al. 2018). In this initial survey, we did not target high-concentration events after rainfall or investigate temporal variability in pesticide concentrations, thus maximum concentrations are not known.

Although varying degrees of biofouling on samplers were observed upon retrieval, there were no obvious relationships between the amount of biofouling and pesticide concentrations. While 
biofouling may affect pesticide uptake rates in POCIS, there is no robust approach for accounting for its effects on sampling rates (Harman et al. 2012). There is no evidence that biofouling affects uptake rates in o-DGT (Challis et al. 2016).

\subsection{Lack of correlation between in-stream pesticide and nutrient concentrations}

DIN concentrations varied widely between the 36 stream sites, from 17.9 to $11,800 \mu \mathrm{g} / \mathrm{L}$, whereas DRP ranged from 2.7 to $94 \mu \mathrm{g} / \mathrm{L}$ (Table S19). No significant correlations ( $p>0.05$ in all cases) were observed between DIN or DRP and the number of detected pesticides, any of the individual pesticide concentrations, or the sum of detected pesticide concentrations (see Figure S3 for representative plots). These results suggest that nutrients and pesticides had different sources and/or that different processes influenced their concentrations at the sampled sites, as previously demonstrated in the chemographs presented by Novic et al. 2018. Our results also show that nutrient concentrations cannot be used as a proxy for expected pesticide concentrations in the sampled streams. In contrast to our findings, a number of significant correlations were reported between individual pesticide concentrations and nitrogen or phosphorus concentrations in a comprehensive investigation on anthropogenic influences on streams and rivers in the US (Appendix 2 in Falcone et al. 2018). Also, a significant correlation was observed between nitrate and pesticide concentrations in groundwater in New Zealand (Close and Skinner 2012). Since we selected our sites based on previous nutrient measurements, an important implication of our finding is that we cannot be confident that our survey included sites with relatively high pesticide loads in New Zealand. Future research should address this important limitation, ideally by sampling streams on agricultural lands where the annual use of pesticides per hectare is known, e.g. Magbanua et al. 2010. 


\subsection{Atrazine concentrations calculated with site-specific POCIS sampling rates}

Site-specific atrazine POCIS sampling rates (Table S9), calculated for the temperatures and flow rates at our sites (Table S1), ranged from 106 to $149 \mathrm{~mL} /$ day for flowing streams and from 43.7 to $58.3 \mathrm{~mL} /$ day for stagnant streams. Challis et al. 2016 suggested a generic representative atrazine POCIS sampling rate of $190 \mathrm{~mL} /$ day, which was the mean of three previously reported values all measured at $\sim 17{ }^{\circ} \mathrm{C}$. Thus, the average site-specific sampling rate was 1.4 times lower than the suggested value for flowing streams and 3.8 times lower for stagnant streams; this resulted in average atrazine concentrations calculated with the site-specific sampling rates being 1.4 and 3.8 times higher for flowing and stagnant streams, respectively. Atrazine concentrations calculated with the two approaches are compared in Table S11, Figure S2, and Figure 4. In many cases, the differences are within the measurement error. For example, at Waikato Site 5, which is a flowing stream, the concentrations calculated with the generic versus site-specific sampling rates are $0.41 \pm 0.27(\mathrm{SD})$ and $0.57 \pm 0.37 \mathrm{ng} / \mathrm{L}$, respectively (Table S10). However, at Waikato Site 6 , which is a stagnant stream, the concentrations calculated with the generic versus site-specific sampling rates are $6.8 \pm 3.0$ and $25 \pm 10 \mathrm{ng} / \mathrm{L}$, respectively (Table S10). We did not re-calculate the POCISderived concentrations for the other pesticides we detected because the Arrhenius parameters have not been determined for those pesticides; nonetheless, their real concentrations are likely also higher by a factor of 2-4 than what we have reported here.

\subsection{Comparison between sampling approaches}

Concentrations from all sampling approaches are compared in Figure 3 and 4, with Figure 4 specifically depicting the number of detections and concentrations obtained for three pesticides at 
the Canterbury sites. Results for atrazine, 2,4-D and imidacloprid are shown in Figure 4 because these pesticides were detected most often in multiple sample types.

Figure 3 shows that most analytes (with the exception of chlorpyrifos, which we will discuss shortly, and clothianidin, which was only found at three sites) were detected more frequently in POCIS than in grab samples. For example, atrazine was detected in POCIS, but not in grab samples, at 23 of 36 sites. Although grab and passive samples represented different time frames, the frequent discrepancy in detection frequency was most likely due to the method detection limit being considerably lower for POCIS than for grab sampling (Table S7). This example portrays how passive sampling can give a more complete view of contaminant loading in streams than grab sampling when concentrations are low.

In contrast to the other detected pesticides, chlorpyrifos was detected almost exclusively in grab samples (Figure 3 and 4). This result was unexpected because chlorpyrifos has been measured successfully with POCIS in a number of previous studies, including at concentrations in the range we measured with grab samples (Alvarez et al. 2014, Zhang et al. 2016, Rico et al. 2019) even the $\log K_{\mathrm{ow}}$ of chlorpyrifos is 4.7 (Table S4) and POCIS is generally considered useful for analytes with $\log K_{\mathrm{ow}}<3$ (Alvarez 2010). It is noteworthy that a particularly wide range of POCIS sampling rates for chlorpyrifos has been reported, with values including $130 \mathrm{~mL} /$ day (Lissalde et al. 2011), $50 \mathrm{~mL} /$ day (Ahrens et al. 2015), and 4.3-6.8 mL/day (depending on temperature) (Yabuki et al. 2016). An explanation for this wide range of reported rates is not obvious; however, it is possible that we did not observe chlorpyrifos in POCIS if the conditions at our sites (perhaps low flow rates) led to low chlorpyrifos sampling rates. Chlorpyrifos may also sorb to the PES membranes; 
however, our extraction method included solvent rinsing of the PES membranes. Another option is that an unidentified methodological error in chlorpyrifos quantification in POCIS may have occurred; however, we followed well-established POCIS protocols (Carlson et al. 2013) with extraction and sample treatment procedures similar to those that we used for solid-phase extraction with grab samples.

The performance of the o-DGT and MPT samplers at the Canterbury sites can also be evaluated by comparing the pesticide detection frequencies and concentrations obtained with these two sampler types to those obtained with POCIS. For example, atrazine was detected with POCIS at 11 of 12 Canterbury sites, but at only 6 and 5 of these sites in MPT and o-DGT samplers, respectively (Figure 4a). The decreased detection frequency of atrazine in MPT and o-DGT samplers was likely due to its lower sampling rate in these samplers than in POCIS (Table S7). The MPT and o-DGT samplers were designed with thicker diffusive membranes than POCIS (the diffusive membrane thicknesses were $0.132 \mathrm{~mm}$ for POCIS, $2 \mathrm{~mm}$ for MPT, and $0.75 \mathrm{~mm}$ for oDGT). In passive samplers for polar analytes, increasing the thickness of the diffusive membrane decreases the sampling rate, which has the advantages of increasing the kinetic regime time and decreasing the effects of water flow rate on the sampling rate, but the disadvantage of decreasing analyte detectability at low concentrations. Our study is a good example of a scenario in which a sampler with a thinner diffusive member, such as POCIS, was advantageous since atrazine concentrations were too low for detection at all sites by MPT or o-DGT. One option for future work is to increase the MPT or o-DGT sampling rates by increasing the sampler surface area, as discussed in Challis et al. 2016. 
2,4-D was detected in MPT samplers at seven stream sites, but at only four sites each in POCIS and o-DGT (Figure 4b). 2,4-D had a particularly low POCIS sampling rate compared to other pesticides (Table S7); this diminished the detection limit advantage that POCIS offered for atrazine. Imidacloprid was detected at just three sites and at particularly low concentrations; however, it was detected in both POCIS and MPT in all cases (Figure 4c). The concentrations obtained for atrazine, 2,4-D, and imidacloprid were remarkably similar for the different samplers (Figure 4); this indicates that the novel MPT and o-DGT samplers trialed in our study can be used successively for pesticide analysis in steams when concentrations are high enough.

\subsection{Potential Concerns for Aquatic Organisms}

We compared the highest measured concentrations from our 36 stream sites to the 21-day 'No Observable Effect Concentrations' (NOEC) from standard laboratory ecotoxicology tests for fish (using rainbow trout, fathead minnows or Japanese rice fish) and aquatic invertebrates (using the microcrustacean Daphnia magna) (University of Hertfordshire 2018) (Table S20). The chlorpyrifos concentration at Waikato Site 1 and Canterbury Site 7 (both $180 \mathrm{ng} / \mathrm{L}$ ) were higher than the NOEC value for fish $(140 \mathrm{ng} / \mathrm{L})$; moreover, the measured chlorpyrifos concentrations exceeded $50 \%$ of the NOEC values at three other sites. It is clear from these results, combined with the high detection frequency for this insecticide discussed earlier, that more monitoring of chlorpyrifos in New Zealand streams is needed and mitigation strategies may be needed.

The concentrations of the other pesticides we detected were much lower than the NOEC values (Table S20). Nevertheless, it is well established that the standard species used in NOEC tests are generally far less sensitive to pesticide exposure than other aquatic species. For example, stream 
mayfly larvae can be six orders of magnitude more sensitive to neonicotinoids than the lake zooplankter Daphnia magna (Morrissey et al. 2015). The NZ Environmental Protection Authority has calculated Environmental Exposure Limits (EELs) for hazardous substances (New Zealand Environmental Protection Authority 2018). However, only two of the seven pesticides targeted for analysis at all 36 sites are included on the EEL list: imidacloprid, with an EEL in water of $38 \mathrm{ng} / \mathrm{L}$, and thiamethoxam, with an EEL of $350 \mathrm{ng} / \mathrm{L}$. The EEL for imidacloprid is around four times higher than the maximum concentration in our study $(10 \mathrm{ng} / \mathrm{L})$. Given that surface runoff often increases pesticide concentrations by several orders of magnitude (Morrissey et al. 2015, Novic et al. 2018), imidacloprid EEL values could be exceeded after rainfall events at our stream sites. Moreover, as pointed out above we cannot be confident that our stream survey included sites with relatively high loads of neonicotinoids or other pesticides.

A final important implication of our findings is that aquatic organisms in New Zealand's agricultural streams are clearly being exposed to a complex mixture of multiple pesticides, and this can lead to additive or synergistic multiple-stressor effects. Besides pesticides, organisms in agricultural streams are typically exposed to several other stressors, for example increased levels of dissolved nutrients and fine sediment, raised water temperatures, and/or reduced stream flow e.g. (Matthaei et al. 2010, Piggott et al. 2012). A recent meta-analysis has shown that multiplestressor effects can increase the effects of toxicants by up to 100 times (Liess et al. 2016).

\section{ACKNOWLEDGEMENTS}

We thank the Natural Sciences and Engineering Research Council of Canada Discovery Grant and the Canada Research Chairs Program for funding for CSW. We also thank Garth Tyrell (University of Otago) for assistance with field gear design, Chris Paxman (University of Queensland) for assistance with PFMs, and Kevin Stroski (University of Manitoba) for assistance with o-DGTs. 


\section{REFERENCES}

Ahrens, L., Daneshvar, A., Lau, A. E. and Kreuger, J. (2015). Characterization of five passive sampling devices for monitoring of pesticides in water. Journal of Chromatography A 1405: 1-11.

Allinson, G., Allinson, M., Bui, A., Zhang, P., Croatto, G., Wightwick, A., Rose, G. and Walters, R. (2016). Pesticide and trace metals in surface waters and sediments of rivers entering the Corner Inlet Marine National Park, Victoria, Australia. Environmental Science and Pollution Research 23: 5881-5891.

Allinson, G., Bui, A., Zhang, P., Rose, G., Wightwick, A., Allinson, M. and Pettigrove, V. (2014). Investigation of 10 herbicides in surface waters of a horticultural production catchment in southeastern Australia. Archives of Environmental Contamination and Toxicology 67: 358-373.

Allinson, G., Bui, A., Zhang, P., Rose, G., Wighwick, M., Allinson, M. and Pettigrove, V. (2014). Investigation of 10 herbicides in surface waters of a horticultural production catchment in southeastern Australia. Archives of Environmental Contamination and Toxicology 358-373.

Alvarez, D. A. (2010). Guidelines for the use of semipermeable membrane device (SMPD) and the polar organic chemical integrative sampler (POCIS) in environmental monitoring studies: US Geological Survey, Techniques and Methods 1-D4.

Alvarez, D. A., Huckins, J. N., Petty, J. D., Jones-Lepp, T. L., Stuer-Lauridsen, F., Getting, D. T., Goddard, J. P. and Gravell, A. (2007). Tool for monitoring hydrophilic contaminants in water: polar organic chemical integrative sampler (POCIS). Passive Sampling Techniques in Environmental Monitoring, Comprehensive Analytical Chemistry. R. Greenwood, G. A. Mills and B. Vrana. Amsterdam, Elsevier. 48.

Alvarez, D. A., Perkins, S., Nilsen, E. and Morace, J. (2014). Spatial and temporal trends in occurrence of emerging and legacy contaminants in the Lower Columbia River 2008-2010. Science of the Total Environment 484: 322-330.

Alvarez, D. A., Petty, J. D., Huckins, J. N., Jones-Lepp, T. L., Getting, D. T., Goddard, J. P. and Manahan, S. E. (2004). Development of a passive, in situ, integrative sampler for hydrophilic organic contaminants in aquatic environments. Environmental Toxicology and Chemistry 23: 1640-1648.

APHA. (1998). Standard Methods for the Examination of Water and Wastewater, 20th Edition, American Public Health Organization, Washington DC, USA.

Bethsass, J. and Colangelo, A. (2013). European Union bans atrazine, while the United States negotiates continued use. International Journal of Occupational and Environmental Health 12: 260-267.

Bradley, P. W., Journey, C. A., Romanok, K. M., Barber, L. B., Buxton, H. T., Foreman, W. T., Furlong, E. T., Glassmeyer, S. T., Hladik, M. L., Iwanowicz, L. R., Jones, D. K., Kolpin, D., Kuivila, K. M., Loftin, K. A., Mills, M. A., Meyer, M. T., Orlando, J. L., Reilly, T. J., Smalling, 
K. L. and Villeneuve, D. L. (2017). Expanded target-chemical analysis reveals extensive mixedorganic-contaminant exposure in U.S. streams. Environmental Science \& Technology 51: 47924802 .

Bundschuh, M., Goedkoop, W. and Kreuger, J. (2014). Evaluation of pesticide monitoring strategies in agricultural streams based on the toxic-unit concept - Experiences from long-term measurements. Science of the Total Environment 484: 84-91.

Carlson, J. C., Challis, J. K., Hanson, M. L. and Wong, C. S. (2013). Stability of pharmaceuticals and other polar organic compounds stored on polar organic chemical integrative samplers and solid-phase extraction cartridges. Environmental Toxicology and Chemistry 32: 337-344.

Challis, J. K., Hanson, M. L. and Wong, C. S. (2016). Development and calibration of an organicdiffusive gradients in thin films aquatic sampler for a diverse suite of polar organic contaminants. Analytical Chemistry 88: 10583-10591.

Chapman, R. B. (2010). A review of insecticide use on pastures and forage crops in New Zealand.

Close, M. E. and Skinner, A. (2012). Sixth National survey of pesticides in groundwater in New Zealand. New Zealand Journal of Marine and Freshwater Research 46: 443-457.

Djomte, V., Taylor, R. B., Chen, S., Booij, K. and Chambliss, K. (2018). Effects of hydrodynamic conditions and temperature on Polar Organic Chemical Integrative Sampling Rates. Environmental Toxicology and Chemistry 37: 2331-2339.

European Union Policies Information \& Services 2018. Current status of neonicotinoids in the EU, https://ec.europa.eu/food/plant/pesticides/approval_active_substances/approval_renewal/neonico tinoids_en (Accessed December 2018).

Falcone, J. A., Murphy, J. C. and Sprague, L. A. (2018). Regional patterns of anthropogenic influences on streams and rivers in the conterminous United States, from the early 1970s to 2012. Journal of Land Use Science 13: 585-614.

Fauvelle, V., Kaserzon, S. L., Montero, N., Lissalde, S., Allan, I. J., Mills, G. A., Mazzella, N., Mueller, J. F. and Booij, K. (2017). Dealing with flow effects on the uptake of polar compounds by passive samplers. Environmental Science \& Technology 51: 2536-2537.

Fauvelle, V., Montero, N., Mueller, J. F., Banks, A., Mazzella, N. and Kaserzon, S. L. (2017). Glyphosate and AMPA passive sampling in freshwater using a microporous polyethylene diffusion sampler. Chemosphere 188: 241-248.

Gong, X., Li, K., Wu, C., Wang, L. and Sun, H. (2018). Passive sampling for monitoring polar organic pollutants in water by three typical samplers. Trends in Environmental Analytical Chemistry 17: 23-33.

Goulson, D. (2018). Call to restrict neonicotinoids. Science 360: 973. 
Harman, C., Allan, I. J. and Vermeirssen, E. L. M. (2012). Calibration and use of the Polar Organic Chemical Integrative Sampler - A critical review. Envrionmental Toxicology and Chemistry 31: 2724-2738.

Integrated River Basin Management for Europe. The European Union Water Framework Directive, http://ec.europa.eu/environment/water/water-framework/index_en.html (Accessed December 2018).

Islam, F., Wang, J., Farooq, M. A., Khan, M. S. S., Zu, L., Zhu, J., Zhao, M., Muños, S., Li, Q. X. and Zhou, W. (2018). Potential impact of the herbicide 2,4-dichlorophenoxyacetic acid on human and ecosystems. Environment International 111: 332-351.

John, E. M. and Shaike, J. M. (2015). Chlorpyrifos: pollution and remediation. Environmental Chemistry Letters 13: 269-291.

Kaserzon, S. L., Hawker, D. W., Booij, K., O'Brien, S., Kennedy, K., Vermeirssen, E. L. M. and Mueller, J. F. (2014). Passive sampling of perfluorinated chemicals in water: In-situ calibration. Environmental Pollution 186: 98-103.

Kaserzon, S. L., O'Malley, E., Gallen, C., Thompson, K., Paxman, C., O'Brien, J., Eaglesham, G., Ramos, G., Gallen, M.-J., Drage, M. and Wang, X. (2017). Catchment and drinking water quality micropollutant monitoring program - passive sampling, Prepared for Seqwater, https://www.seqwater.com.au/sites/default/files/PDF\%20Documents/Publications/Enclosure\%20 2.2\%20Catchment\%20and\%20Drinking\%20Water\%20Quality\%20Micropollutant\%20Monitorin g\%20Program\%20\%E2\%80\%93\%20Entox\%20Passive\%20Sampling\%20Summer\%2020142015\%20Report.PDF (Accessed May 2019).

Kaserzon, S. L., Vijayasarathy, S., Bräunig, J., Mueller, L., Hawker, D. W., Thomas, K. V. and Mueller, J. F. (2019). Calibration and validation of a novel passive sampling device for the time integrative monitoring of per- and polyfluoroalkyl substances (PFASs) and precursors in contaminated groundwater. Journal of Hazardous Materials 366: 423-431.

Lavin, K. S. and Hageman, K. J. (2013). Contributions of long-range and regional atmospheric transport on pesticide concentrations along a transect crossing a mountain divide. Environmental Science \& Technology 47: 1390-1398.

Lavin, K. S., Hageman, K. J., Marx, S. K., Dillingham, P. and Kamber, B. S. (2012). Using trace elements in particulate matter to identify the sources of semivolatile organic contaminants in air at an alpine site. Environmental Science \& Technology: 268-276.

Liess, M., Foit, K., Knillmann, S., Schäfer, R. B. and Liess, H.-D. (2016). Predicting the synergy of multiple stress effects. Scientific Reports 9: Article Number 32965.

Lissalde, S., Mazzella, N., Fauvelle, V., Delmas, F., Mazellier, P. and Legube, B. (2011). Liquid chromatography coupled with tandem mass spectrometry method for thirty-three pesticides in natural water and comparison of performance between classical solid phase extraction and passive sampling approaches. Journal of Chromatography A 1218: 1492-1502. 
Magbanua, F. S., Townsend, C. R., Blackwell, G. L. and Matthaei, C. D. (2010). Responses of stream macroinvertebrates and ecosystem function to conventional, integrated and organic farming. Journal of Applied Ecology 47: 1014-1025.

Manktelow, D., Stevens, P., Walker, J., Gurnsey, S., Park, N., Zabkiewwicz, J., Teulon, D. and Rahman, A. (2005). Trends in Pesticide Use in New Zealand: 2004, Report to the Ministry for the Environment.

Matthaei, C. D., Piggott, J. J. and Townsend, C. R. (2010). Multiple stressors in agricultural streams: interactions among sediment addition, nutrient enrichment and water abstraction. Journal of Applied Ecology 47: 639-649.

Ministry for the Environment \& Stats NZ. (2017). New Zealand's Environmental Reporting Series: Our fresh water 2017 , www.mfe.govt.nz/sites/default/files/media/Environmental\%20reporting/our-fresh-water2017_1.pdf (Accessed May 2019).

Mitchell, E. A. D., Mulhauser, B., Mulot, M., Mutabazi, A., Glauser, G. and Aebi, A. (2017). A worldwide survey of neonicotinoids in honey. Science 358: 109-111.

Morrissey, C. A., Mineau, P., Devries, J. H., Sánchez-Bayo, F., Liess, M., Cavallaro, M. C. and Liber, K. (2015). Neonicotinoid contamination of global surface waters and associated risk to aquatic invertebrates: A review. Environment International 74: 291-303.

National Institute of Water and Atmosphere 2018. "New Zealand's hottest summer on record." https://www.niwa.co.nz/climate/summaries/seasonal/summer-2017-18 (Accessed December 2018).

New York Times. (2018). Court Orders E.P.A. to Ban Chlorpyrifos, Pesticide Tied to Children's Health Problems, ttps://www.nytimes.com/2018/08/09/us/politics/chlorpyrifos-pesticide-banepa-court.html (Accessed December 2018).

New Zealand Environmental Protection Authority 2018. Controls for Hazardous Substances, https:/www.epa.govt.nz/industry-areas/hazardous-substances/rules-for-hazardoussubstances/controls-for-hazardous-substances/ (Accessed December 2018).

New Zealand Environmental Protection Authority 2018. Priority Chemicals List, https://www.epa.govt.nz/industry-areas/hazardous-substances/chemical-reassessmentprogramme/priority-chemicals-list/ (Accessed December 2018).

Novic, A. J., Ort, C., O'Brien, D., Lewis, S. E., Davis, A. M. and Mueller, J. F. (2018). Understanding the uncertainty of estimating herbicide and nutrient mass loads in a flood event with guidance on estimator selection. Water Research 132: 99-110.

Nowell, L. H., Moran, P. W., Schmidt, T. S., Norman, J. E., Nakagaki, N., Shoda, M. E., Mahler, B. J., Van Metre, P. C., Stone, W. W., Sandstrom, M. W. and Hladik, M. L. (2018). Complex 
mixtures of dissolved pesticides show potential aquatic toxicity in a synoptic study of Midwestern U.S. streams. Science of the Total Environment 613-614: 1469-1488.

Piggott, J. J., Lange, K., Townsend, C. R. and Matthaei, C. D. (2012). Multiple stressors in agricultural streams: a mesocosm study of interactions among raised water temperature, sediment addition and nutrient enrichment. Plos One 7: e49873.

Rico, A., Arenas-Sánchez, A., Alonso-Alonso, C., López, -. H., Isabel, Nozal, L., Rivas-Tabares, D. and Vighi, M. (2019). Identification of contaminatns of concern in the upper Tagus river basin (central Spain). Part 1: Screening, quantitative analysis and comparison of sampling methods. Science of the Total Environment 666: 1058-1070.

Rolando, C. A., Garrett, L. G., Baillie, B. R. and Watt, M. S. (2017). A survey of herbicide use and a review of environmental fate in New Zealand planted forests. New Zealand Journal of Forestry Science 43: 17.

Sánchez-Bayo, F., Goka, K. and Hayasaka, D. (2016). Contamination of the aquatic environment with neonicotinoids and its implication for ecosystems. Frontiers in Environmental Science 4: Article 71.

Sánchez-Bayo, F. and Hyne, R. V. (2014). Detection and analysis of neonicotinoids in river waters - Development of a passive sampler for three commonly used insecticides. Chemosphere 99: 143151.

Shahpoury, P., Hageman, K. J., Matthaei, C. D. and Magbanua, F. S. (2013). Chlorinated pesticides in stream sediments from organic, integrated and conventional farms. Environmental Pollution 181: 219-225.

Singh, S., Kumar, V., Chauhan, A., Datta, S., Wani, A. B., Singh, N. and Singh, J. (2018). Toxicity, degradation and analysis of the herbicide atrazine. Environmental Chemistry Letters 16: 211-237.

Sousa, J. C. G., Ribeiro, A. R., Barbosa, M. O., Pereira, M. F. R. and Silva, A. M. T. (2018). A review of environmental monitoring of water organic pollutants identified by EU guidelines. Journal of Hazardous Materials 334: 146-162.

Stroski, K. M., Challis, J. K. and Wong, C. S. (2018). The influence of pH on sampler uptake for an improved configuration of the organic-diffusive gradients in thin films passive sampler. Analytica Chemica Acta 1018: 45-53.

Szöcs, E., Brinke, M., Karaoglan, B. and Schäfer, R. B. (2017). Large scale risks from agricultural pesticides in small streams. Environmental Science \& Technology 51: 7378-7385.

University of Hertfordshire 2018. Pesticide Properties Database, http://sitem.herts.ac.uk/aeru/ppdb/en/index.htm (Accessed December 2018). 
Urlacher, E., Monchanin, C., Rivière, C., Richard, F.-J., Lombardi, C., Michelsen-Heath, S., Hageman, K. J. and Mercer, A. R. (2016). Measurements of chlorpyrifos levels in forager bees and comparison with levels that disrupt honey bee odor-mediated learning under laboratory conditions. Journal of Chemical Ecology 42: 127-138.

USGS Pesticide National Synthesis Project. United States Geological Survey, https://water.usgs.gov/nawqa/pnsp/ (Accessed December 2018).

Vrana, B., Mills, G. A., Allan, I. J., Dominiak, E., Svensson, K., Knutsson, J., Morrison, G. and Greenwood, R. (2005). Passive sampling techniques for monitoring pollutants in water. Trends in Analytical Chemistry 24: 845-868.

Wu, X., Davie-Martin, C. L., Steinlin, C., Hageman, K., Cullen, N. J. and Bogdal, C. (2017). Understanding and predicting the fate of semivolatile organic pesticides in a glacier-fed lake using a multimedia chemical fate model. Environmental Science \& Technology 51: 11752-11760.

Yabuki, Y., Nagai, T., Inao, K., Ono, J., Aiko, N., Ohtsuka, N., Tanaka, H., Tanimori, S. (2016). Temperature dependence on the pesticide sampling rate of polar organic chemical integrative samplers (POCIS). Bioscience, Biotechnology, and Biochemistry. 80: 2069-2075.

Zabiegała, B., Kot-Wasik, A., Urbanowicz, M. and Namieśnik, J. (2010). Passive sampling as a tool for obtaining reliable analytical information in environmental quality monitoring. Analytical and Bioanalytical Chemistry 396: 273-296.

Zhang, Z., Troldborg, M., Yates, K., Osprey, M., Kerr, C., Hallett, P. D., Baggaley, N., Rhind, S. M., Dawson, J. J. C. and Hough, R. L. (2016). Evaluation of spot and passive sampling for monitoring flux estimation and risk assessment of pesticides within the contraints of a typical regulatory monitoring scheme. Science of the Total Environment 569-570: 1369-1379. 


\section{FIGURES}

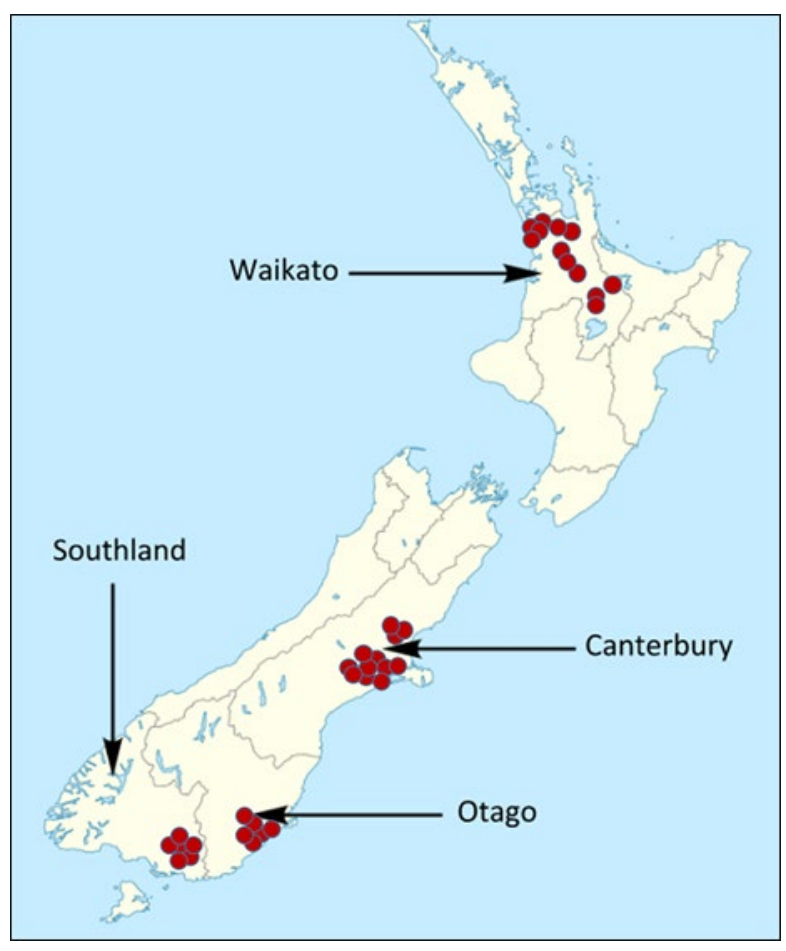

Figure 1. New Zealand Regions where sampling took place. Red dots show approximate locations of stream sites. 


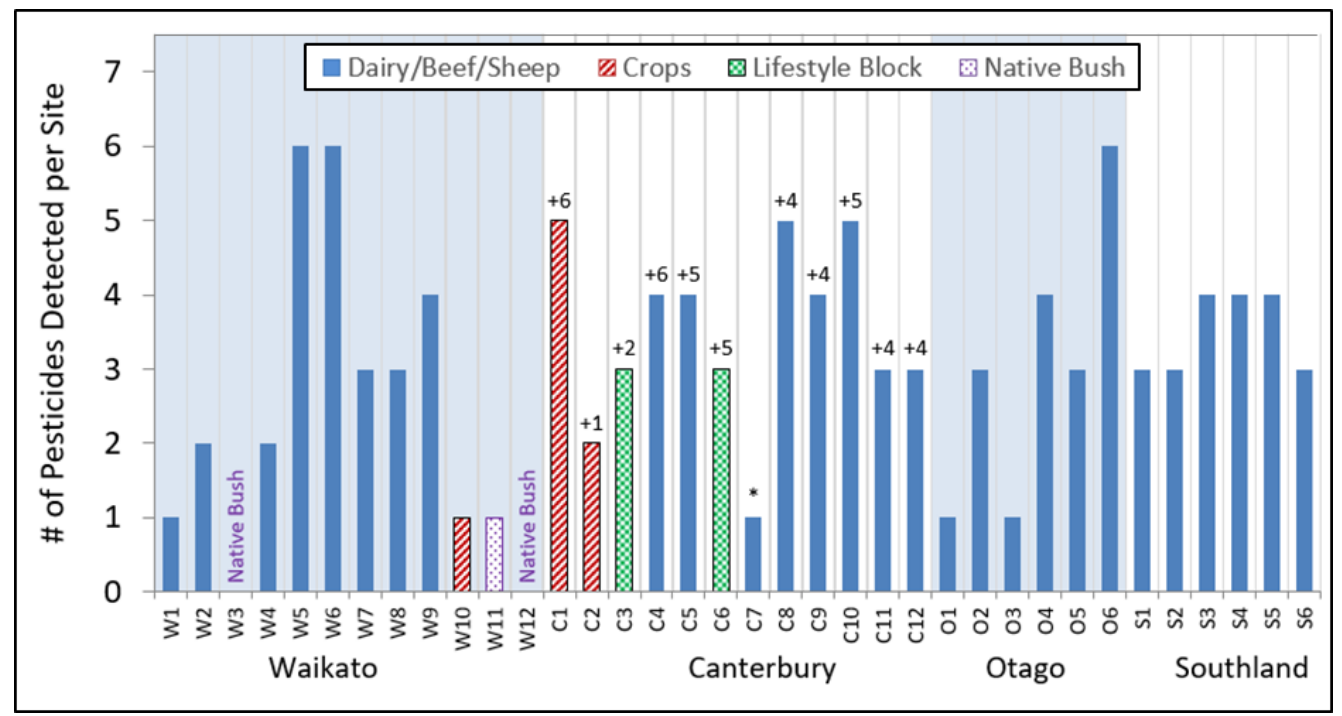

Figure 2. Number of pesticides detected per site by all sampling approaches, with sites arranged by Region and the dominant riparian land use indicated by shading. Data labels indicate the number of additional pesticides or pesticide degradation products detected in MPT samplers at the Canterbury sites; the asterisk above Canterbury Site 7 indicates that the MPT sampler at this site was lost. 

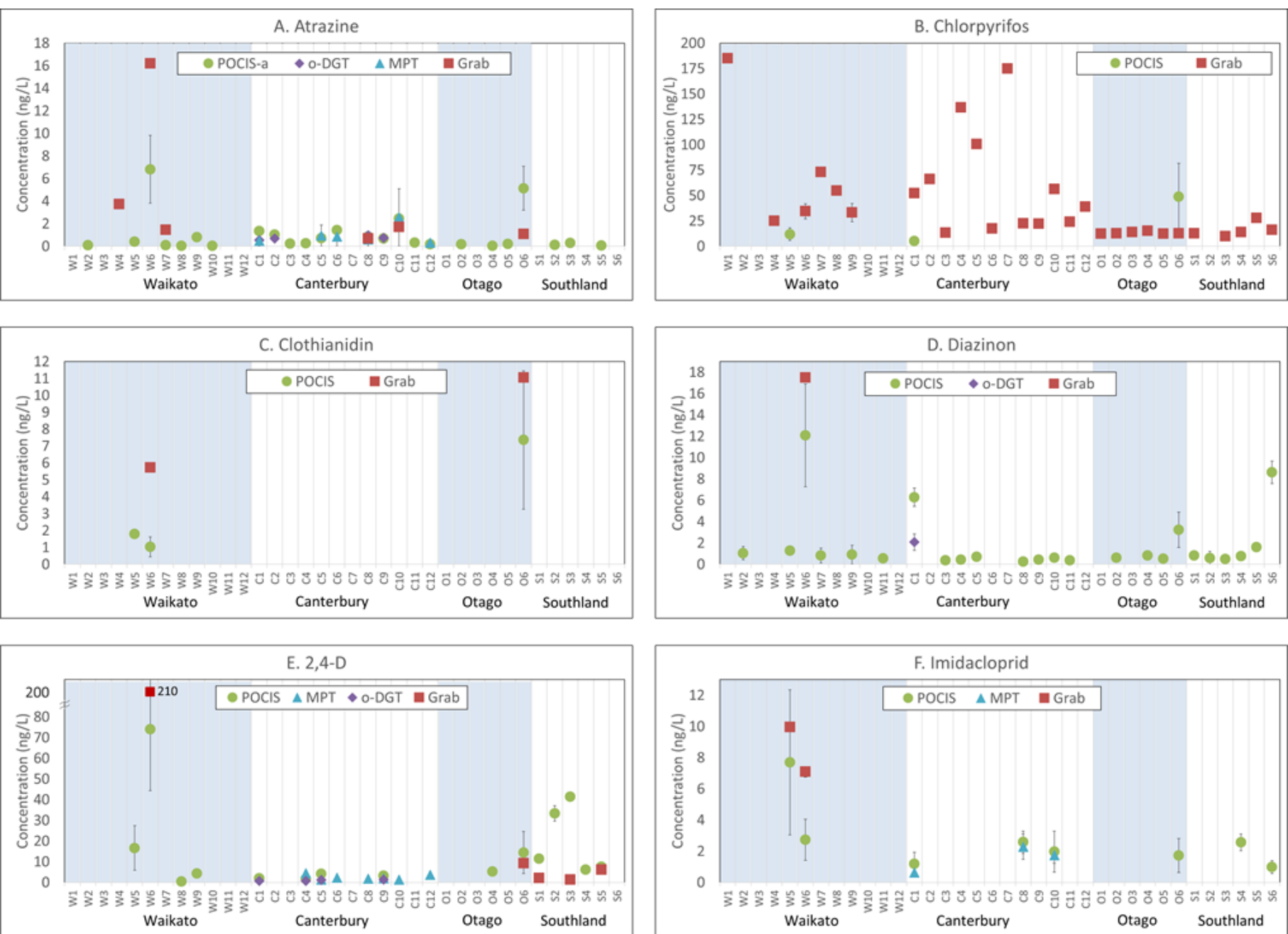

Figure 3. Pesticide concentrations obtained with each sampling approach at each site, with sites arranged according to Region. o-DGT and MPT samplers were only deployed at Canterbury sites. Chlorpyrifos, clothianidin, and diazinon were not targeted for analysis in MPT samplers. No symbols are shown when concentrations were below detection limits. Error bars indicate one standard deviation. 

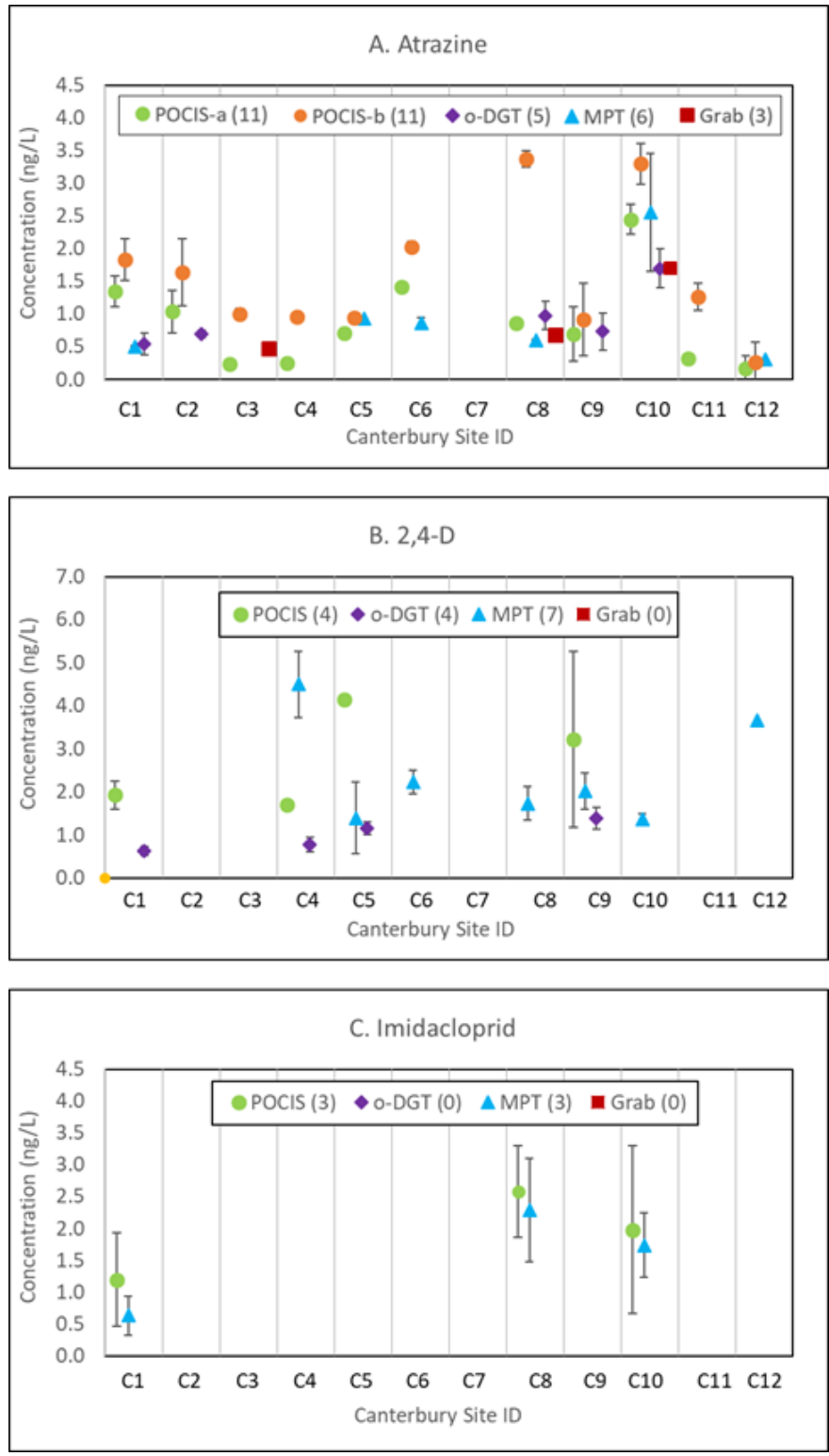

Figure 4. Pesticide concentrations obtained with each sampling approach at the Canterbury sites, where all four sampling approaches were employed. The numbers in parentheses indicate the number of detects for that sampling approach. In panel A, POCIS-a concentrations were calculated with the generic POCIS sampling rate, whereas POCIS-b concentrations were calculated with the site-specific POCIS sampling rates. Error bars indicate one standard deviation. 